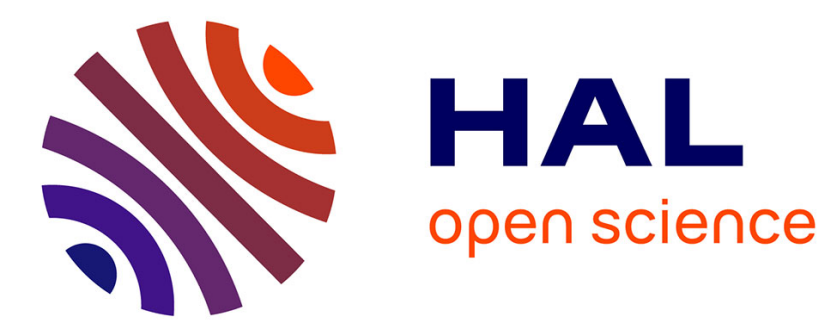

\title{
Tuning color variation in grape anthocyanins at the molecular scale.
}

Laura Rustioni, Florent Di Meo, Maxime Guillame, Osvaldo Failla, Patrick

Trouillas

\section{- To cite this version:}

Laura Rustioni, Florent Di Meo, Maxime Guillame, Osvaldo Failla, Patrick Trouillas. Tuning color variation in grape anthocyanins at the molecular scale.. Food Chemistry, 2013, 141 (4), pp.4349-57. 10.1016/j.foodchem.2013.07.006 . inserm-00845052

\section{HAL Id: inserm-00845052 https://www.hal.inserm.fr/inserm-00845052}

Submitted on 16 May 2014

HAL is a multi-disciplinary open access archive for the deposit and dissemination of scientific research documents, whether they are published or not. The documents may come from teaching and research institutions in France or abroad, or from public or private research centers.
L'archive ouverte pluridisciplinaire HAL, est destinée au dépôt et à la diffusion de documents scientifiques de niveau recherche, publiés ou non, émanant des établissements d'enseignement et de recherche français ou étrangers, des laboratoires publics ou privés. 


\section{Accepted Manuscript}

Tuning Color Variation In Grape Anthocyanins At The Molecular Scale

Laura Rustioni, Florent Di Meo, Maxime Guillaume, Osvaldo Failla, Patrick

Trouillas

PII:

S0308-8146(13)00927-8

DOI:

http://dx.doi.org/10.1016/j.foodchem.2013.07.006

Reference:

FOCH 14349

To appear in:

Food Chemistry

Sciverse Sciencedirect

Received Date:

23 April 2013

Revised Date:

28 June 2013

Accepted Date:

1 July 2013

Please cite this article as: Rustioni, L., Di Meo, F., Guillaume, M., Failla, O., Trouillas, P., Tuning Color Variation In Grape Anthocyanins At The Molecular Scale, Food Chemistry(2013), doi: http://dx.doi.org/10.1016/j.foodchem. 2013.07.006

This is a PDF file of an unedited manuscript that has been accepted for publication. As a service to our customers we are providing this early version of the manuscript. The manuscript will undergo copyediting, typesetting, and review of the resulting proof before it is published in its final form. Please note that during the production process errors may be discovered which could affect the content, and all legal disclaimers that apply to the journal pertain. 
1 Tuning Color Variation In Grape Anthocyanins At The Molecular Scale

2

3

4

5

6

7

25

26

27 CIRIVE Centro Interdipartimentale di ricerca per l'innovazione in Viticoltura ed Enologia

28 via Celoria 2

29 I-20133 Milano

30 ITALY

31 Tel.: +390250316556

32 Fax: +390250316553

33 E-mail: laura.rustioni@unimi.it

Trouillas $\mathrm{s}^{\mathrm{b}, \mathrm{d}} \mathrm{d}$ Viticoltura ed Enologia, via Celoria 2, I-20133 Milano, Italy France Belgium

${ }^{\mathrm{d}}$ Regional Center of Advanced Technologies and Materials, Department of Physical Chemistry, Faculty of Science, Palacký University, 17. listopadu 1192/12, 77146 Olomouc, Czech Republic

${ }^{a}$ Università degli Studi di Milano, CIRIVE - Centro Interdipartimentale di ricerca per l'innovazione in

b Inserm, UMR-S850, Faculté de Pharmacie, Université de Limoges, 2 rue du Dr Marcland, 87000 Limoges,

x, Université de Mons, Place du Parc, 20, B-7000, Mons, 


\section{ABSTRACT}

35 Anthocyanins are the main grape pigments. Due to their aromatic cyclic arrangements, they 36 are able to absorb the radiation in the low energy range of the visible spectrum. In the fruit of 37 Vitis vinifera L., the five main anthocyanidins (cyanidin, peonidin, delphinidin, petunidin and 38 malvidin) are present as 3-O-glucosides, as well as their acetyl, $p$-coumaroyl and caffeoyl 39 ester forms. Despite the huge number of experimental studies dedicated to the anthocyanin 40 profile analysis of grapes and wines, the complete theoretical elucidation of the optical 41 properties of grape anthocyanins is missing. The present work carried out this task through 42 quantum chemistry calculations based on time-dependent density functional theory (TD43 DFT), compared to experimental spectra. The differences in visible absorption spectra 44 between the most common grape anthocyanins were rationalized according to B-ring 45 substitution, glucosylation and esterification. A particular attention was given to the intra46 molecular copigmentation effect, demonstrating the existence of an intra-molecular charge 47 transfer excited state for the $p$-coumaroyl and caffeoyl ester forms.

49 KEYWORDS: UV/Vis absorption, intra-molecular copigmentation, optical properties, 50 pigment profile, TD-DFT, grape anthocyanins, wine 


\section{INTRODUCTION}

53 Anthocyanins are a class of $\pi$-conjugated compounds belonging to polyphenols. They are

54 glycosides of the so-called anthocyanidins, characterized by a flavylium (2-phenyl55 benzylpyrilium) skeleton (Fig. 1). The many possible chemical substitutions (with e.g., $\mathrm{OH}$ 56 and OMe groups) allow a large variety of compounds. They are pigments responsible for the 57 shiny orange, pink, red, violet and blue colors in roots, stems, flowers and fruit of many plants 58 (e.g., orchids, grapes) (Castañeda-Ovando, Pacheco-Hernández, Páez-Hernández, Rodríguez $59 \&$ Galán-Vidal, 2009). Such a color variety is mainly driven by the capacity of these 60 compounds to absorb green light (at around $520 \mathrm{~nm}$ ), which has generally been attributed to 61 the resonant structure of the flavylium cation (Allen, 1998; Castañeda-Ovando, et al., 2009).

62 This was confirmed by quantum chemistry calculations, showing a highly delocalized $\pi$ 63 conjugated system, spread over the entire molecule (Di Meo, Sancho Garcia, Dangles \& 64 Trouillas, 2012). This extended $\pi$-conjugation allows light absorption in the visible range 65 rather than the violet to ultraviolet regions as it is described and theoretically rationalized for 66 most of the other natural polyphenols (Anouar, Gierschner, Duroux \& Trouillas, 2012).

67 A thorough understanding of optical properties and pigmentation variation has become crucial 68 in various domains including food and wine chemistry. We believe that in a near future 69 fundamental rationalization of grape pigments should become mandatory to supporting the 70 development of fast and non-invasive phenotyping strategies (Rustioni, Basilico, Fiori, Leoni, 71 Maghradze \& Failla, 2013). In grapes and wines, five anthocyanidin moieties are present in 72 their glucosylated form, namely peonidin, cyanidin, malvidin, petunidin and delphinidin (Fig.

73 1a). The most common anthocyanin in Vitis vinifera L. (i.e., the common wine grape specie) 74 is malvidin-3-O-glucoside (Kennedy, Saucier \& Glories, 2006). There also exist anthocyanins 75 having their glucose moiety attached to a carboxylic acid (acetic, $p$-coumaric and caffeic acids 76 in Vitis vinifera L.) by an ester bond, giving rise to a group of acylated pigments (Fig. 1b) 
77 (Allen, 1998). In the latter structures, intra-molecular copigmentation effects have been 78 suggested (Dangles, Saito \& Brouillard, 1993).

79 Despite all the available experimental studies focusing on the grape and wine anthocyanin 80 profiles (Dallas \& Laureano, 1994; Ferrandino, Guidoni \& Mannini, 2007; Fischer, Löchner 81 \& Wolz, 2006; García-Puente Rivas, Alcalde-Eon, Santos-Buelga, Rivas-Gonzalo \& 82 Escribano-Bailón, 2006; Mattivi, Guzzon, Vrhovsek, Stefanini \& Velasco, 2006; Roggero, 83 Coen \& Ragonnet, 1986; Rustioni, Rossoni, Calatroni \& Failla, 2011; Rustioni, Rossoni, 84 Cola, Mariani \& Failla, 2011; Rustioni, Rossoni, Failla \& Scienza, 2013), a profound 85 understanding of the optical variability of these compounds is still missing. Quantum chemistry calculation is an adapted tool for investigation of these properties. In particular time dependent density functional theory (TD-DFT) enables to accurately characterize excited states and evaluate the subsequent absorption properties in the visible range. More than providing accurate absorption wavelengths, TD-DFT calculations provide a complete description of the excited states and thus allow full assignment of electronic transitions from the $\pi$ to $\pi^{*}$ molecular orbitals (MO) responsible for each UV/Vis absorption band. In this way, the method supports the tuning of pigmentation in various industrial applications e.g., 93 pigment painting and solar cells. Moreover the intra-molecular interactions suggested from experience (Dangles, et al., 1993) can now be accurately evaluated by quantum calculations; these interactions are known to be responsible for copigmentation, but the process was only 96 recently fully understood using dispersion-corrected DFT (DFT-D) calculations (Di Meo, et 97 al., 2012).

98 The present work aims at rationalizing the differences in the absorption spectra between a 99 series of grape anthocyanins, which has not been performed yet for these compounds. The series studied here is constituted of five glucosylated (compounds 1-5 in Figure 1a) and three acylated anthocyanins (compounds 6-8 in Figure 1b), which were investigated due to their 
102 high occurrence in grape. This comprehensive study allows establishing a thorough structure-

103 property relationship for grape anthocyanins. In addition and as a new insight, the

104 copigmentation effects are carefully rationalized for the acylated anthocyanins.

105

MATERIAL AND METHODS

\section{Experimental data}

108 The grape anthocyanin spectra were collected from our database of HPLC chromatograms

109 obtained in 2008, within the framework of the study on competitive copigmentation

110 interactions (Rustioni, Bedgood Jr, Failla, Prenzler \& Robards, 2012). Anthocyanins were

111 extracted from the skin of Shiraz and Sangiovese berries. The primary pigment solutions were

112 prepared after the careful removal of skin from 30 berries, and suspended in a $60 \mathrm{~mL}$ model-

113 wine-buffer solution (12\% ethanol and $2.5 \mathrm{~g} \mathrm{~L}^{-1}$ tartaric acid adjusted at $\mathrm{pH} 3.3$ with aqueous

$114 \mathrm{NaOH}$ ). The pigment extracts were obtained by filtration after this mixture was shacked for 6

115 hours. The extracts were characterized on a Varian Prostar 240I HPLC (Mulgrave, Vic,

116 Australia) using a Phenomenex Gemini $5 \mu \mathrm{m} \mathrm{C18} \mathrm{110A} 250$ x 4.6 mm column (Lane Cove,

117 NSW, Australia), with a Phenomenex SecurityGuard column, operated at $25^{\circ} \mathrm{C}$. For the

118 HPLC separation the mobile phase was water:formic acid:acetonitrile $(87: 10: 3 \mathrm{v} / \mathrm{v} / \mathrm{v}$, eluent

$119 \mathrm{~A} ; 40: 10: 50 \mathrm{v} / \mathrm{v} / \mathrm{v}$, eluent B), and the following gradient sequence was used: from 10 to $25 \%$

$120 \mathrm{~B}(10 \mathrm{~min})$, from 25 to $31 \% \mathrm{~B}(5 \mathrm{~min})$, from 31 to $40 \% \mathrm{~B}(5 \mathrm{~min})$, from 40 to $50 \% \mathrm{~B}$ (10

$121 \mathrm{~min})$, from 50 to $100 \% \mathrm{~B}(10 \mathrm{~min})$ from 100 to $10 \% \mathrm{~B}(5 \mathrm{~min})$, as previously described by

122 Kammerer et al. (Kammerer, Claus, Carle \& Schieber, 2004). The flow rate was $0.8 \mathrm{~mL} \mathrm{~min}^{-}$

123 . The eluent was monitored by a Varian Prostar 335 photodiode array detector (Mulgrave,

124 Vic, Australia). Peak identification was achieved using both the retention time and the LCMS

125 analysis as previously described (Rustioni, et al., 2012). 
Malvidin aglycone, and caffeic and p-coumaric acids (SIGMA-ALDRICH) were used

127 without further purification. To compare their spectra with those obtained in HPLC, three

128 solutions $\left(10 \mathrm{mg} \mathrm{L}^{-1}\right.$ for malvidin, $5.7 \mathrm{mg} \mathrm{L}^{-1}$ for caffeic acid and $3.2 \mathrm{mg} \mathrm{L}^{-1}$ for $p$-coumaric

129 acid) were prepared using the same solvent as for the HPLC elution (water:formic

130 acid:acetonitrile 65:10:25 v/v/v). A Jasco $7800 \mathrm{UV}$-Vis spectrophotometer was used to record

131 absorption spectra from 200 to $600 \mathrm{~nm}$.

132 Considering the high percentage of formic acid providing $\mathrm{pH}$ ca. 1.6, the flavylium cation

133 form of the anthocyanins is unambiguously predominant. For this reason and for the sake of 134 comparison with experimental data, all the theoretical calculations were performed 135 considering this cationic form.

\section{Theoretical methodology}

138 Over the past decade, the density functional theory (DFT) has been validated and extensively

139 used to evaluate conformational, electronic and optical properties of natural polyphenols

140 (Anouar, Gierschner, Duroux \& Trouillas, 2012; Trouillas, Marsal, Siri, Lazzaroni \& Duroux,

141 2006). TD-DFT turned out to be an accurate theoretical method to describe excited states and

142 consequently UV/Visible properties at an acceptable computational time for medium-size

143 polyphenols, namely containing up to 200 atoms (Anouar, et al., 2012; Nave, et al., 2012).

144 Hybrid functionals succeeded at describing most of polyphenol properties; the B3P86

145 functional has appeared particularly adapted to assess both their thermodynamic (Trouillas, et 146 al., 2006) and UV/Visible absorption properties (Anouar, et al., 2012). Using the Pople-type 147 triple- $\zeta$ basis set, TD-B3P86/6-311+G(d,p) allowed to establish reliable structure property 148 (UV/Visible absorption) relationships for large series of polyphenols, at a reasonable 149 computational time (Anouar, et al., 2012; Millot, Di Meo, Tomasi, Boustie \& Trouillas, 150 2012). 
B3P86 was thus extrapolated for the present work to evaluate both conformation and

152 UV/Visible absorption properties of peonidin, cyanidin, malvidin, petunidin and delphinidin 153 and their glucoside derivatives (Fig. 1).

154 Concerning the acylated derivatives, cofacial (non-covalent) intra-molecular interactions

155 were examined between the anthocyanidin and the phenolic acyl (i.e., $p$-coumaroyl and

156 caffeoyl) moieties. It is well described that classical hybrid functionals fail at describing these

157 non-covalent interactions, which are mainly dispersive effects (e.g., $\pi$-stacking, $\nu$ - $\pi$ and long-

158 distance H-bonds). The empirical dispersion-corrected DFT (DFT-D) is a successful approach

159 to evaluate these non-covalent complexation, also allowing to circumvent the use of high-

160 costing post-HF methods (Grimme, 2006). Our recent parameterization of the B3P86-D2

161 functional provided very reliable results to describe non-covalent interaction in polyphenols

162 and copigmentation (anthocyanidin:flavonol) complexes with respect to both post-HF

163 methods and experiments (Di Meo, et al., 2012). Therefore in the present work, the ground

164 state geometries of the acylated derivatives were corrected according to this empirical

165 dispersion correction. The cc-pVDZ basis set was used, which has appeared sufficient to

166 reach accuracy, with respect to high-level quantum calculations and experimental data, in the

167 description of anthocyanidin:flavonol complexation. ${ }^{1}$ All DFT-D calculations were achieved

168 within the resolution of identity (RI) approximation, dramatically decreasing the

169 computational time with a negligible error (Neese, Wennmohs, Hansen \& Becker, 2009).

170 When working with DFT-D(B3P86-D2), the geometries were obtained with the ORCA

171 package (Neese, 2012). In the other case i.e., when working with B3P86 (no dispersion

172 correction), the geometries were calculated with GAUSSIAN09 (Frisch, et al., 2009). All TD-

173 DFT calculations were achieved with GAUSSIAN09.

\footnotetext{
${ }^{1}$ It must be stressed that dispersion-corrected B3P86-D2 functional has been assessed and validated within double-z basis set precision.
} 
Solvent effects were taken into account using implicit solvent models, in which the solute

175 is embedded in a shape-adapted cavity surrounded by a dielectric continuum. Even if they do

176 not explicitly account for inter-molecular interaction between solute and solvent, implicit

177 solvent models have allowed reaching accuracy to evaluate various properties of polyphenols,

178 including optical properties (Anouar, et al., 2012; Millot, et al., 2012). The qualitative

179 description of the influence of solvent polarity is particularly relevant, which perfectly

180 reproduce structure-property relationships. Methanol $(\varepsilon=32.61)$ was used to simulate the

181 polarity of the experimental conditions used to measure the UV/Visible spectra. The

182 conductor-like screening model (COSMO) (Sinnecker, Rajendran, Klamt, Diedenhofen \&

183 Neese, 2006) and the integral-equation formalism polarizable continuum model (IEFPCM)

184 (Cossi, Scalmani, Rega \& Barone, 2002) were used with ORCA and GAUSSIAN09, 185 respectively.

\section{RESULTS AND DISCUSSION}

$188 \mathrm{UV}$ /Visible absorption properties of grape 3-O-glucosylated anthocyanins

189 The experimental spectra measured for the five 3-O-glucosylated anthocyanidins

190 (compounds 1-5 namely cyanidin 3-O-glucoside, peonidin 3-O-glucoside, delphinidin 3-O-

191 glucoside, petunidin 3-O-glucoside and malvidin 3- $O$-glucoside - also called oenin - as seen

192 in Fig. 1), synthesized in grape berries, consist of three main peaks experimentally located at

193 around i) $520 \mathrm{~nm}$ (Band I), ii) $440 \mathrm{~nm}$ (Band II) and iii) $330 \mathrm{~nm}$ (Band III) (Fig. 2a). The di-

194 substituted B-ring compounds (i.e., cyanidin 3-O-glucoside and peonidin 3-O-glucosides)

195 have an additional absorption band located at around $375 \mathrm{~nm}$ (Band $\left.\mathrm{II}_{\mathrm{b}}\right)$.

196

197 Molecular orbital rationalization of Band I - The highest absorption wavelength $\lambda_{\max }$

198 corresponding to Band I of compounds 1-5 are 516, 517, 524, 526 and $527 \mathrm{~nm}$, respectively 
199 (Table 1). As already described for anthocyanidins, this wavelength is slightly underestimated

200 by TD-DFT calculations when using standard hybrid functionals (Anouar, et al., 2012; Chai

$201 \&$ Head-Gordon, 2008). This band corresponds to a transition from the ground state $\left(\mathrm{S}_{0}\right)$ to the

202 first excited state $\left(\mathrm{S}_{1}\right)$ and is mainly assigned to the HOMO (highest occupied molecular 203 orbital) to LUMO (lowest unoccupied molecular orbital) electronic transition. ${ }^{2}$ In order to

204 simplify notations, the HOMO $\rightarrow$ LUMO electronic transition is quoted $\mathrm{H} \rightarrow \mathrm{L}$ throughout the

205 text. Both molecular orbitals (MO) are delocalized over the whole anthocyanidin moiety (Fig.

$2063 a \& b)$. This allows an efficient overlap between the two molecular orbitals involved in the

207 transition, which provides relatively high oscillator strengths (and therefore high absorption

208 intensities) for all five compounds ( $f$ around 0.60 as seen in Table 1$).$

209 The compounds having a tri-substituted B-ring (compounds 3-5), exhibit a (red)-

210 bathochromic shift compared to the di-substituted (1 and 2) derivatives (Fig. 2a). This is

211 attributed to the $(+\mathrm{M})$ mesomeric effect that slightly but significantly extends $\pi$-conjugation

212 in the B-ring, which subsequently lowered the H-L gap ( $\Delta \mathrm{E}_{\text {gap }}$, Fig. 3a\&b). When adding one

213 OH group (i.e., compounds 1 vs. 3 and 2 vs. 4), both $\mathrm{H}$ and L are stabilized but to a lower

214 extent for $\mathrm{H}$, thus decreasing the gap (e.g., $\Delta \mathrm{E}_{\text {gap }}$ decreases from 2.91 to $2.86 \mathrm{eV}$, from 1 to 3 ,

215 see Fig. 3a\&b). Such an effect was similarly observed for aglycone flavonoids.(Anouar, et al.,

216 2012) When replacing an OH group by an OMe group, both frontier MOs are destabilized, but

217 the $\mathrm{H}$ orbital is more impacted by this destabilization, resulting in the decrease of the H-L gap

218 (e.g., $\Delta \mathrm{E}_{\text {gap }}$ is 2.86 and $2.75 \mathrm{eV}$ for $\mathbf{3}$ and $\mathbf{5}$, respectively, see $\mathrm{S} 1$ ).

219 The theoretical excited states of the aglycone counterpart of compounds 1-5 were also 220 evaluated for the sake of comparison. From this comparison, it appears that the sugar moiety

\footnotetext{
${ }^{2}$ In the present work, the orbital analysis is based on the 3D distribution of only the main two MO involved in the main electronic transition. The full analysis taking the contributions of all electronic transitions into account was also achieved (see Supplement Information). However, this latter (thorough) analysis does not influence the conclusions (except concerning one point, which is mentioned in the next footnote); thus for the sake of simplicity, the simpler analysis is kept in the main body of the text.
} 
221

222

223

224

225

226

227

228

229

230

231

232

233

234

235

236

237

238

239

240

241

creates new MOs lying below H-4 (see Supplementary Information), which do not directly influence the absorption spectra e.g., by the formation of new bands. However, the sugar addition induces a slight increase of the H-L gap, due to both the stabilization of $\mathrm{H}$ and destabilization of $\mathrm{L}$. This is in agreement with experimental data, as it results in a significant hypsochromic shift of Band I in the glucosides' spectra (e.g., $\lambda_{\max }$ equal 527 and $536 \mathrm{~nm}$ for compound 5 and its aglycone counterpart, respectively as seen in Fig. 2b). This does not influence the global spectra, which are similar in shape with both forms.

Molecular orbital rationalization of Band II - Band II appears in the experimental spectra as a shoulder of the maximum absorption band, which is located at around $440 \mathrm{~nm}$ (Fig. 2a). It corresponds to the second excited state $\left(\mathrm{S}_{2}\right)$ and is mainly assigned to the $\mathrm{H}-1 \rightarrow \mathrm{L}$ and $\mathrm{H}-$ $2 \rightarrow \mathrm{L}$ for di-substituted (i.e., compounds 1 and 2) and tri-substituted (i.e., compounds 3-5) compounds, respectively (Table 1). L being delocalized on the $\mathrm{A}$ and $\mathrm{C}$ rings, this shoulder appears attributed to this moiety. A thorough analysis of the MO spatial distribution highlights interconversion between both $\mathrm{H}-1$ and $\mathrm{H}-2$ for the di- and tri-substituted compounds; that is, the spatial distribution of $\mathrm{H}-1$ in the di-substituted compound is similar to that of H-2 in the tri-substituted compound (Fig. 3a\&b). These MOs are delocalized over the entire anthocyanidin moiety. Moreover, they exhibit the same energy ( $c a .-7.75 \mathrm{eV}$ for all compounds, as seen in Supplementary Information). For the tri- substituted compounds, H-1 is delocalized over the B-ring only. This MO slightly contributes to other excited states, including $\mathrm{S}_{1}$ (data not shown).

For the di-substituted compounds ( $\mathbf{1}$ and $\mathbf{2})$, there exists a specific absorption band, quoted Band $\mathrm{II}_{\mathrm{b}}$ in Table 1 , which is absent in the experimental spectra of the tri-substituted compounds (3, 4 and 5). Quantum chemistry calculations fully rationalize this experimentally observed difference. Band $\mathrm{II}_{\mathrm{b}}$ is assigned to the $\mathrm{H}-2 \rightarrow \mathrm{L}$ electronic transition. In the disubstituted compounds, H-2 is slightly delocalized on the A\&C-rings (Fig. 3a), allowing 
246 electronic transitions with low oscillator strengths $(f=0.15$ and 0.18 for $\mathbf{1}$ and 2,

247 respectively). In the tri-substituted compounds, due to the MO redistribution described above,

$248 \mathrm{H}-1$ is almost fully delocalized on the B-ring, preventing this electronic transition involving

249 the A\&C-rings. Moreover, in this case, the energetic difference between $\mathrm{H}-1$ and $\mathrm{L}$ is

250 lowered. Thus for the tri-substituted compounds, Band $\mathrm{II}_{\mathrm{b}}$ is weak and red-shifted; it cannot

251 be experimentally observed under classical conditions (i.e., room temperature and classical

252 resolutions).

253

254

255

256

257

258

259

260

261

262

263

264

265

266

267

268

269

Molecular orbital rationalization of Band III - Band III is mainly assigned to the $\mathrm{H}-4 \rightarrow \mathrm{L}$ electronic transition. In agreement with the experimental data, Band III exhibits relatively low oscillator strengths compare to those of Band $\mathrm{I}$, for all five compounds ( $f$ is ranging from 0.02 to 0.08 , see Table 1). The (blue)hypsochromic shift experimentally observed from the tri- to the di-substituted compounds (e.g., $\lambda=348$ and $328 \mathrm{~nm}$ for 5 and $\mathbf{1}$, respectively, see Table 1) is rationalized by the influence of the sugar moiety, which surprisingly, but in full agreement with the experimental data, borrows part of the $\mathrm{H}-4$ orbital, in the di-substituted compounds (Fig. 3a\&b). In this case the sugar moiety stabilizes H-4, thus increasing the energy difference between H-4 and L, inducing the hypsochromic shift. This is probably only an (energetic) indirect effect, as the electronic excitation does not involve the sugar moiety (Fig. S2). ${ }^{3}$

\section{UV/Visible absorption properties of grape acylated anthocyanins}

The spectral modulation related to esterification is discussed for the malvidin derivatives, as they are the main grape anthocyanidins.

\footnotetext{
${ }^{3}$ This is clearly observed when analyzing all MO involved in this electronic transition.
} 
Conformational analysis - Concerning the three malvidin 3-O-glucoside esters

271 (compounds 6, 7 and 8, see Fig. 1) one, two (7A and 7B) and two (8A and 8B) conformers

272 were obtained, respectively (Fig. 4).

273 For each possible conformer, the Boltzmann distribution percentages $\mathrm{D}_{\text {Bolt }}$ were estimated

274 (Table 2) from the relative energies $\Delta \mathrm{E}_{\text {relative }}$ (as calculated between all conformers with 275 B3P86-D2/cc-pVDZ), according to the following formula:

276

$$
D_{\text {Bolt }}=\exp \left(-\frac{\Delta E_{\text {relative }}}{R T}\right) \text {, }
$$

where $\mathrm{R}$ is the ideal gas constant and T equals $298 \mathrm{~K}$.

278 The non-covalent intra-molecular interactions between the acyl and anthocyanidin moieties 279 play a crucial role in the stabilization of these conformers. A strong H-bond (distance lower 280 than $1.65 \AA$ ) between the $5-\mathrm{OH}$ and the ester keto groups is observed in $\mathbf{6}, \mathbf{7 B}, \mathbf{8 A}$ and $\mathbf{8 B}$

281 (Fig. 4). A weaker $\mathrm{H}$-bond is observed between the 5-OH and the $\mathrm{O}$ atom involved in the 282 esterification (distance of $2.39 \AA$ ) for 7A. Other non-covalent interactions are observed in 7A, 7B and 8A (Fig. 4), namely i) one H-bonding between the 7-OH and the 4"-OH groups

284 (distance of 1.80 and $2.27 \AA$, respectively) for 7A and 7B, which is not present in compound 8 285 as $4 "$ "-OH is absent in this case, and ii) $\pi$-stacking interaction in $\mathbf{7 B}$ and $\mathbf{8 A}$ (distance of 4.20 $286 \AA$ ).

287 The conformation populations of 7 and $\mathbf{8}$, show a predominance of $7 \mathrm{~A}\left(\mathrm{D}_{\mathrm{Bolt}}=90 \%\right)$ and 288 8A $\left(\mathrm{D}_{\text {Bolt }}=83 \%\right)$ for both compounds, respectively. This clearly suggests that both H-bonding 289 and $\pi$-stacking interactions are the driving forces of this intra-molecular folding. UV/Visible absorption spectra of 6, 7 and 8: a matter of intra-molecular copigmentation -

292 When compared to the glycosilated malvidin (5), the experimental spectra of $\mathbf{6}, 7$ and 8 293 clearly show the influence of esterification, mainly in the presence of the phenolic acid moiety 
294 (compounds 7 and 8). The three acylated anthocyanins exhibit an experimental bathochromic 295 shift of Band I that is lower for $\mathbf{6}(\Delta \lambda \max$ around 2, 5 and $4 \mathrm{~nm}$ for $\mathbf{6}, 7$ and $\mathbf{8}$, respectively).

296 The bathochromic shift of Band I is mainly rationalized by $\pi$-stacking complexation. In 297 conformations 7B and 8A, the maximum absorption wavelength (related to Band I) and other 298 very close absorption wavelengths are assigned to the $\mathrm{H} \rightarrow \mathrm{L}$ and $\mathrm{H}-1 \rightarrow \mathrm{L}$ electronic transitions 299 (Table 2a). In all conformers, H and L are mainly delocalized on the anthocyanin moiety (Fig. $3003 \mathrm{c}-\mathrm{f})$, and the electron transition presents no charge-transfer character. In the particular case of 301 conformers $\mathbf{7 B}$ and $\mathbf{8 A}, \mathrm{H}$ is slightly located on the phenolic ring of the ester moiety (Fig. $3023 \mathrm{~d} \& \mathrm{e})$. This can be better evaluated by the LCAO (linear combination of atomic orbital) 303 coefficients, which reflect the atomic weight of a given $\mathrm{MO}$. For $\mathrm{H}$ of $\mathbf{7 B}$ and $\mathbf{8 A}$, these 304 coefficients are $13 \%$ and $21 \%$ on the acyl moiety, respectively (Table S2). However, a 305 detailed analysis of MO contributions (see Supplementary Information) shows that the 306 esterification affects neither the spatial distribution nor the energy of $\mathrm{H}$ and L, showing that 307 the bathochromic shift is not rationalized by the $\mathrm{H} \rightarrow \mathrm{L}$ contribution. The main contribution to 308 the modification of the excited state (with respect to that of compound 5) comes from H-1, 309 which is highly delocalized over the phenolic ester moiety for all conformers of 7 and 8 (Fig. $3103 \mathrm{c}-\mathrm{f})$. Therefore the $\mathrm{H}-1 \rightarrow \mathrm{L}$ electronic transition exists only because of the formation of a 311 charge transfer excited state (CT-ES), inducing a global bathochromic shift attributed to

312 esterification. In conformers $\mathbf{7 B}$ and $\mathbf{8 A}, \mathrm{H}-1$ is also located on the anthocyanin moiety (the

313 LCAO coefficients of $\mathrm{H}$ are $57 \%$ and $49 \%$ on the anthocyanin moiety, for $\mathbf{7 B}$ and $\mathbf{8 A}$, 314 respectively see Table S2), which increases the corresponding oscillator strength (Table 2).

315 Compound 7 exhibits a slightly lower experimental bathochromic shift than $8(\Delta \lambda \max =4$

316 and $5 \mathrm{~nm}$, for both compounds respectively, see Table 2a). In contrast, the theoretical 317 bathochromic shift is higher with the former compound (7) i.e., 24.7 vs. $18.9 \mathrm{~nm}$, for both 318 compounds respectively (Table 2a). This is consistent with the higher electron donor capacity 
319 of the ortho-dihydroxyphenyl (catechol) moiety. Thus the lower experimental bathochromic

320 shift observed for $\mathbf{7}$ is attributed to a lower population of the $\pi$-stacked conformation (7B) in

321 solution compared to that of $\mathbf{8}(\mathbf{8 A})$. This highlights the importance of i) charge-transfer in the

322 excited state and ii) populations for all the possible copigmentation complexes, as already 323 shown in our previous work (Di Meo, et al., 2012).

324

325

A new band $\left(I I_{b}\right)$ at $330 \mathrm{~nm}$ - The acylated compounds exhibit a new absorption band, quoted Band $\mathrm{III}_{\mathrm{b}}$, experimentally located at around $330 \mathrm{~nm}$ (Fig. 2c), which is somehow a modulation of Band III. This band is actually the sum of the minor anthocyanic absorption

328 Band III (Table 1 and Fig. 2a) and the (red)bathochromic-shifted band mainly attributed to the stand-alone phenolic acid (e.g., $\lambda=324$ and $336 \mathrm{~nm}$ for caffeic acid and the caffeoyl ester of malvidin 3-O-glucoside, respectively and $\lambda=309.6$ and $316 \mathrm{~nm}$ for $p$-coumaric acid and the $p$-coumaroyl ester of malvidin 3-O-glucoside, respectively, see Table $2 \mathrm{~b}$ and Fig. $2 \mathrm{c}$ ). It is

332 theoretically assigned to several contributions predominantly $\mathrm{H}-1 \rightarrow \mathrm{L}+1, \mathrm{H}-4 / 5 / 6 \rightarrow \mathrm{L}$ and

$333 \mathrm{H} \rightarrow \mathrm{L}+2$ electronic transitions (Table $2 \mathrm{~b}$ ). The first contribution is purely attributed to the 334 phenol acid moiety, both MO being delocalized on this moiety. These MO are stabilized in 335 the presence of the anthocyanin moiety, $\mathrm{H}$ being more stabilized than $\mathrm{L}$, which should induce 336 a hypsochromic shift. The global bathochromic shift is due to the other two contributions.

337 Among these contributions, the $\mathrm{H}-4 \rightarrow \mathrm{L}$ contribution corresponds to that already observed for 338 compound 5, as the main contribution of Band III.

CONCLUSION

341 Grapes and wines represent agricultural product of utmost importance in food industry.

342 The color of the final product is a major descriptor of quality. A deep understanding of the 343 optical properties of the main Vitis vinifera L. pigments represents an effective support for the 
344 industries to address market requirements. This is mandatory to develop new analytical

345 methods based on the optical properties and to deeply understand fruit potential. As described

346 above, quantum chemistry calculations have allowed elucidating the structure (optical)

347 properties of a series of grape pigments. These calculations provide a molecular picture of the

348 pigments as well as a molecular orbital description of the excited states related to the different

349 absorption bands responsible for color. Subtle effects such as copigmentation can also be

350 explained by using the adapted theoretical methodologies, namely DFT-D. All the theoretical

351 data support the experimental observations. The full MO description of light absorption, in the

352 visible range, enables to tune optical properties (according to the chemical structures of the

353 different grape pigments), and subsequently color variation. Quantum calculation can now be

354 considered as a promising analytical tool for wine industry. 


\section{AKNOWLEDGEMENTS}

356 The authors acknowledge Prof. Paul Prenzler (School of Agricultural and Wine Sciences, 357 Charles Sturt University, Wagga Wagga, NSW, Australia) for the availability to share the 358 HPLC results.

359 The authors thank the French embassy for the financial support in the framework of the 360 "Borse di ricerca scientifica dell'Ambasciata di Francia" project; the "Conseil Régional du 361 Limousin" for financial support and CALI (CAlcul en LImousin) for computing facilities.

362 Research in Limoges is also supported by the COST action CM0804 "Chemical Biology with

363 Natural Compounds". The authors gratefully acknowledge the support by the Operational 364 Program Research and Development for Innovations-European Regional Development Fund 365 (project CZ.1.05/2.1.00/03.0058 of the Ministry of Education, Youth and Sports of the Czech 366 Republic). Research in Mons is supported by BELSPO (PAI 7/05), Région Wallonne 367 (OPTI2MAT Excellence program) and FNRS-FRFC.

368 This work is a joint publication of the COST Action FA1003 "East-West Collaboration for 369 Grapevine Diversity Exploration and Mobilization of Adaptive Traits for Breeding". 


\section{TABLES}

371 Table 1. Theoretical excitation energies (E, eV), absorption wavelengths $(\lambda, \mathrm{nm})$, oscillator 372 strengths $(f)$, main electronic transition contribution and experimental absorption wavelength $373\left(\lambda_{\text {exp }}, \mathrm{nm}\right)$ of anthocyanidin 3-O-glucosides. The calculations (excited states + geometries) 374 were performed with IEFPCM-B3P86/6-311+G(d,p).

375

\begin{tabular}{|c|c|c|c|c|c|c|}
\hline Band & Compound & E & $\lambda$ & $f$ & $\begin{array}{l}\text { Electronic transition } \\
\text { contribution }\end{array}$ & $\lambda_{\exp }$ \\
\hline \multirow[t]{5}{*}{ I } & 1 & 2.59 & 478.0 & 0.58 & $\mathrm{H} \rightarrow \mathrm{L}(67 \%)$ & 516 \\
\hline & 2 & 2.57 & 482.8 & 0.59 & $\mathrm{H} \rightarrow \mathrm{L}(68 \%)$ & 517 \\
\hline & 3 & 2.57 & 482.8 & 0.57 & $\mathrm{H} \rightarrow \mathrm{L}(67 \%)$ & 524 \\
\hline & 4 & 2.56 & 483.4 & 0.61 & $\mathrm{H} \rightarrow \mathrm{L}(68 \%)$ & 526 \\
\hline & 5 & 2.49 & 497.1 & 0.59 & $\mathrm{H} \rightarrow \mathrm{L}(68 \%)$ & 527 \\
\hline \multirow[t]{5}{*}{ II } & 1 & 2.95 & 419.8 & 0.07 & $\mathrm{H}-1 \rightarrow \mathrm{L}(67 \%)$ & $\sim 440$ \\
\hline & 2 & 2.92 & 424.8 & 0.03 & $\mathrm{H}-1 \rightarrow \mathrm{L}(68 \%)$ & $\sim 440$ \\
\hline & 3 & 2.95 & 420.1 & 0.11 & $\mathrm{H}-2 \rightarrow \mathrm{L}(67 \%)$ & $\sim 440$ \\
\hline & 4 & 2.93 & 423.7 & 0.06 & $\mathrm{H}-2 \rightarrow \mathrm{L}(67 \%)$ & $\sim 440$ \\
\hline & 5 & 2.92 & 424.0 & 0.05 & $\mathrm{H}-2 \rightarrow \mathrm{L}(68 \%)$ & $\sim 440$ \\
\hline \multirow[t]{5}{*}{$\mathrm{II}_{\mathrm{b}}$} & 1 & 3.23 & 384.0 & 0.15 & $\mathrm{H}-2 \rightarrow \mathrm{L}(70 \%)$ & 373 \\
\hline & 2 & 3.22 & 385.2 & 0.18 & $\mathrm{H}-2 \rightarrow \mathrm{L}(69 \%)$ & 375 \\
\hline & 3 & 2.68 & 463.2 & 0.03 & $\mathrm{H}-1 \rightarrow \mathrm{L}(70 \%)$ & - \\
\hline & 4 & 2.70 & 456.0 & 0.01 & $\mathrm{H}-1 \rightarrow \mathrm{L}(70 \%)$ & - \\
\hline & 5 & 2.68 & 461.9 & 0.07 & $\mathrm{H}-1 \rightarrow \mathrm{L}(70 \%)$ & - \\
\hline \multirow[t]{5}{*}{ III } & 1 & 3.88 & 319.5 & 0.02 & $\mathrm{H}-4 \rightarrow \mathrm{L}(62 \%)$ & 328 \\
\hline & 2 & 3.88 & 319.8 & 0.02 & $\mathrm{H}-4 \rightarrow \mathrm{L}(62 \%)$ & 328 \\
\hline & 3 & 3.73 & 332.2 & 0.06 & $\mathrm{H}-4 \rightarrow \mathrm{L}(66 \%)$ & 346 \\
\hline & & 3.72 & 332.9 & 0.08 & $\mathrm{H}-4 \rightarrow \mathrm{L}(66 \%)$ & 347 \\
\hline & 5 & 3.69 & 336.2 & 0.08 & $\mathrm{H}-4 \rightarrow \mathrm{L}(66 \%)$ & 348 \\
\hline
\end{tabular}


Table 2. Theoretical excitation energies $(\mathrm{E}, \mathrm{eV})$, absorption wavelengths $(\lambda, \mathrm{nm})$, oscillator strengths $(f)$, electronic transition contribution and experimental absorption wavelength $\left(\lambda_{\text {exp }}\right.$, $\mathrm{nm}$ ) of the different optimized conformation of acetyl (6), caffeyl (7) and $p$-coumaryl (8) esters of malvidin 3-O-glucoside, and related theoretical and experimental bathochromic shifts ( $\Delta \lambda$ th and $\Delta \lambda \exp , \mathrm{nm}$ ) concerning (a) Band I and (b) Band III. Boltzmann distributions $D_{\text {Boltz }}$ are expressed in \%. The calculations were performed with IEFPCMB3P86/6-311+G(d,p)//COSMO-B3P86(D2)/cc-pVDZ.

(a)

\begin{tabular}{|c|c|c|c|c|c|c|c|c|c|}
\hline Ester & Conformation & $\mathrm{D}_{\text {Boltz }}$ & $\mathrm{E}$ & $\lambda$ & $f$ & $\begin{array}{l}\text { Electronic } \\
\text { transition } \\
\text { contribution }\end{array}$ & $\Delta \lambda \operatorname{th}^{a}$ & & \\
\hline Acetic ester & 6 & $90 \%$ & 2.51 & 494.9 & 0.58 & $\mathrm{H} \rightarrow \mathrm{L}(68 \%)$ & -2.2 & 529 & 2 \\
\hline \multirow[t]{4}{*}{$\begin{array}{l}\text { Caffeoyl } \\
\text { ester }\end{array}$} & 7A & $90 \%$ & 2.47 & 502.2 & 0.17 & $\begin{array}{l}\mathrm{H}-1 \rightarrow \mathrm{L}(57 \%) \\
\mathrm{H} \rightarrow \mathrm{L}(40 \%)\end{array}$ & 5.0 & 531 & 4 \\
\hline & & & 2.50 & 496.5 & 0.38 & $\mathrm{H} \rightarrow \mathrm{L}(54 \%)$ & -0.6 & & \\
\hline & 7B & $6 \%$ & 2.38 & 521.8 & 0.10 & $\mathrm{H}-1 \rightarrow \mathrm{L}(52 \%)$ & 24.7 & & \\
\hline & & & 2.49 & 498.1 & 0.37 & $\begin{array}{l}\mathrm{H}-1 \rightarrow \mathrm{L}(46 \%) \\
\mathrm{H} \rightarrow \mathrm{L}(49 \%)\end{array}$ & 1.0 & & \\
\hline \multirow{3}{*}{$\begin{array}{l}p \text { - } \\
\text { Coumaroyl } \\
\text { ester }\end{array}$} & $\mathbf{8 A}$ & $83 \%$ & 2.40 & 516.0 & 0.41 & $\mathrm{H} \rightarrow \mathrm{L}(66 \%)$ & 18.9 & 532 & 5 \\
\hline & & & 2.59 & 479.5 & 0.03 & $\mathrm{H}-1 \rightarrow \mathrm{L}(58 \%)$ & & & \\
\hline & 8B & $15 \%$ & 2.50 & 495.2 & 0.57 & $\mathrm{H} \rightarrow \mathrm{L}(67 \%)$ & -1.9 & & \\
\hline
\end{tabular}

\footnotetext{
${ }^{a}$ the shift is performed with respect to malvidin 3-O-glucoside $\lambda_{\max }$.
} (b)

\begin{tabular}{|c|c|c|c|c|c|c|c|c|c|}
\hline \multirow{2}{*}{ Ester } & \multirow{2}{*}{ Conformation } & \multirow{2}{*}{$D_{\text {boltz }}$} & \multirow{2}{*}{$\mathrm{E}$} & \multirow{2}{*}{$\lambda$} & \multirow{2}{*}{$f$} & \multirow{2}{*}{$\begin{array}{c}\text { Electronic transition } \\
\text { contribution }\end{array}$} & \multirow{2}{*}{$\Delta \lambda t h$} & \multicolumn{2}{|r|}{ Exp } \\
\hline & & & & & & & & $\lambda_{\exp }$ & $\Delta \lambda \exp$ \\
\hline Acetic ester & 6 & 100 & 3.64 & 340.8 & 0.07 & $\mathrm{H}-3 \rightarrow \mathrm{L}(65 \%)$ & nd & 348 & nd \\
\hline \multirow{8}{*}{$\begin{array}{l}\text { Caffeoyl } \\
\text { ester }\end{array}$} & $7 \mathrm{~A}$ & & 3.66 & 339.1 & 0.03 & $\mathrm{H}-5 \rightarrow \mathrm{L}(48 \%)$ & 1.1 & 324 & 12 \\
\hline & & & & & & $\mathrm{H}-6 \rightarrow \mathrm{L}(36 \%)$ & & & \\
\hline & & & & & & $\mathrm{H}-1 \rightarrow \mathrm{L}+1(31 \%)$ & & & \\
\hline & & & & & & $\mathrm{H} \rightarrow \mathrm{L}+2(15 \%)$ & & & \\
\hline & & & 3.72 & 333.5 & 0.64 & $\mathrm{H}-1 \rightarrow \mathrm{L}+1(62 \%)$ & -4.5 & & \\
\hline & & $6 \%$ & 3.51 & 353.7 & 0.32 & $\mathrm{H}-1 \rightarrow \mathrm{L}+1(68 \%)$ & 15.7 & & \\
\hline & & & & & & $\mathrm{H}-4 \rightarrow \mathrm{L}+1(10 \%)$ & & & \\
\hline & & & 3.64 & 340.5 & 0.03 & $\mathrm{H}-5 \rightarrow \mathrm{L}(65 \%)$ & 2.5 & & \\
\hline \multirow{11}{*}{$\begin{array}{l}p \text {-Coumaroyl } \\
\text { ester }\end{array}$} & $\mathbf{8 A}$ & $83 \%$ & 3.68 & 336.6 & 0.25 & $\mathrm{H}-1 \rightarrow \mathrm{L}+1(55 \%)$ & 19.6 & 316 & 6 \\
\hline & & & & & & $\mathrm{H}-5 \rightarrow \mathrm{L}(33 \%)$ & & & \\
\hline & & & 3.74 & 331.5 & 0.22 & $\mathrm{H}-5 \rightarrow \mathrm{L}(47 \%)$ & 14.5 & & \\
\hline & & & & & & $\mathrm{H}-1 \rightarrow \mathrm{L}+1(34 \%)$ & & & \\
\hline & & & & & & $\mathrm{H} \rightarrow \mathrm{L}+2(15 \%)$ & & & \\
\hline & 8B & $15 \%$ & 3.70 & 334.8 & 0.68 & $\mathrm{H}-1 \rightarrow \mathrm{L}+1(64 \%)$ & 17.7 & & \\
\hline & & & & & & $\mathrm{H}-4 \rightarrow \mathrm{L}+(14 \%)$ & & & \\
\hline & & & 3.75 & 331.1 & 0.13 & $\mathrm{H}-6 \rightarrow \mathrm{L}(62 \%)$ & 14.0 & & \\
\hline & & & & & & $\mathrm{H}-4 \rightarrow \mathrm{L}(20 \%)$ & & & \\
\hline & & & & & & $\mathrm{H}-1 \rightarrow \mathrm{L}+1(19 \%)$ & & & \\
\hline & & & & & & H-6 $\rightarrow \mathrm{L}(15 \%)$ & & & \\
\hline
\end{tabular}


$387 a^{a}$ the shift is performed with respect to the stand-alone acid $\lambda_{\max }$ (i.e., caffeic or p-coumaric acid in solution).

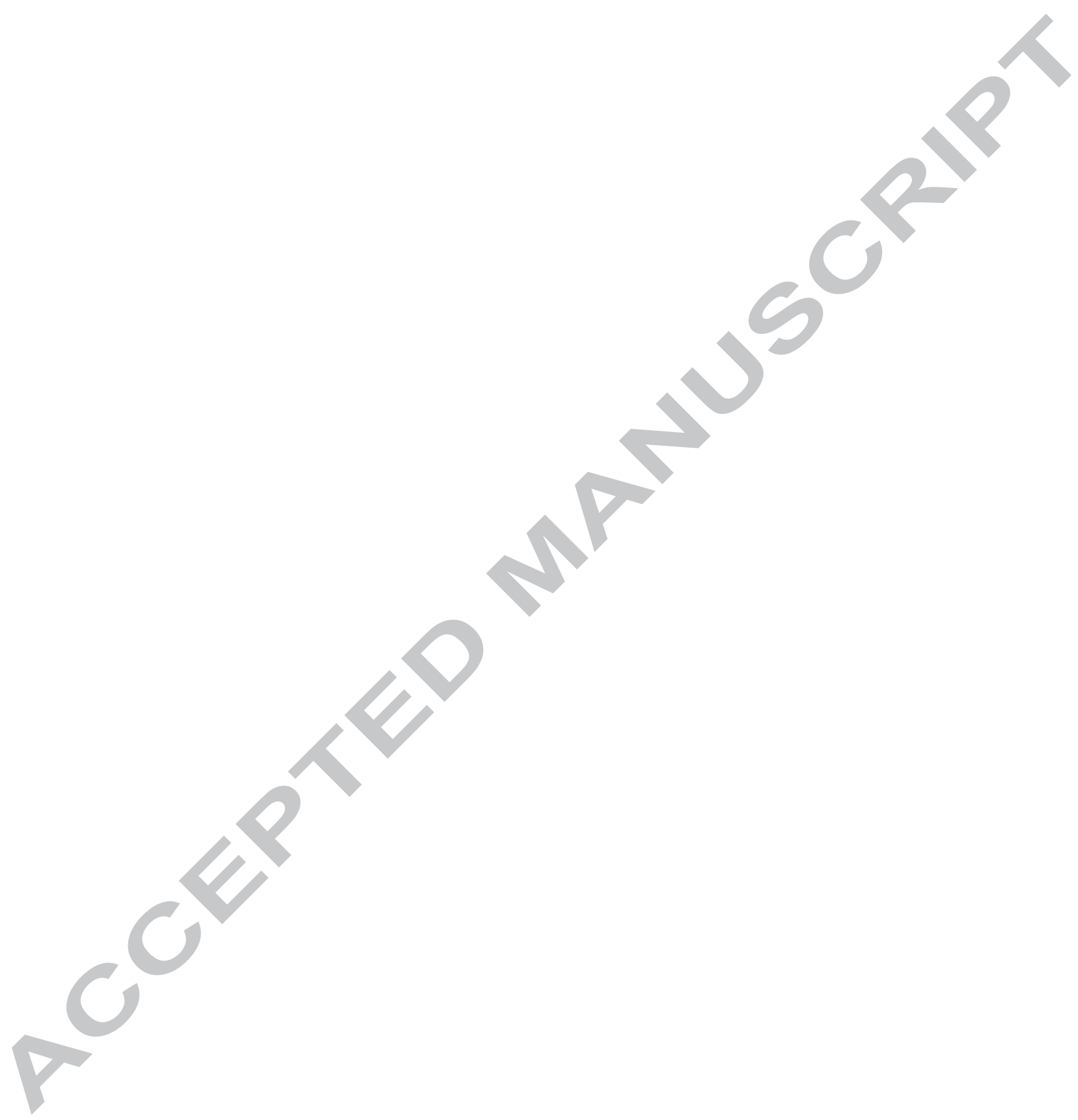




\section{REFERENCES}

Allen, M. (1998). Phenolics and Extraction. In A. S. o. V. a. Oenology (Ed.), Proceedings ASVO, Accepted). Adelaide.

Anouar, E. H., Gierschner, J., Duroux, J.-L., \& Trouillas, P. (2012). UV/Visible spectra of natural polyphenols: A time-dependent density functional theory study. Food Chemistry, $131,79-89$.

394 Castañeda-Ovando, A., Pacheco-Hernández, M. d. L., Páez-Hernández, M. E., Rodríguez,

395 J. A., \& Galán-Vidal, C. A. (2009). Chemical studies of anthocyanins: A review. Food 396 Chemistry, 113, 859-871.

397 Chai, J.-D., \& Head-Gordon, M. (2008). Long-range corrected hybrid density functionals 398 with damped atom-atom dispersion corrections. Physical Chemistry Chemical Physics, 10, $399 \quad 6615-6620$.

400 Cossi, M., Scalmani, G., Rega, N., \& Barone, V. (2002). New developments in the 401 polarizable continuum model for quantum mechanical and classical calculations on 402 molecules in solution. Journal of Chemical Physics, 117, 43-54.

403 Dallas, C., \& Laureano, O. (1994). Effect of SO2 on the extraction of individual 404 anthocyanins and colored matter of three Portuguese grape varieties during winemaking. 405 Vitis, Accepted.

406 Dangles, O., Saito, N., \& Brouillard, R. (1993). Anthocyanin intramolecular copigment 407 effect. Phytochemistry, 34, 119-124.

408 Di Meo, F., Sancho Garcia, J. C., Dangles, O., \& Trouillas, P. (2012). Highlights on 409 Anthocyanin Pigmentation and Copigmentation: A Matter of Flavonoid $\pi$-Stacking 410 Complexation To Be Described by DFT-D. Journal of Chemical Theory and Computation, $4118,2034-2043$. 
412 Ferrandino, A., Guidoni, S., \& Mannini, F. (2007). Grape quality parameters and 413 polyphenolic content of different 'Barbera' and 'Nebbiolo' (Vitis vinifera L.) clones as 414 influenced by environmental conditions - preliminary results. Acta Horticulturae, 754, $415 \quad 437-442$.

416 Fischer, U., Löchner, M., \& Wolz, S. (2006). Red Wine Authenticity: Impact of 417 Technology on Anthocyanin Composition. In Authentication of Food and Wine, vol. 952 418 (pp. 239-253): American Chemical Society.

419 Frisch, M. J., Trucks, G. W., Schlegel, H. B., Scuseria, G. E., Robb, M. A., Cheeseman, J. 420 R., Scalmani, G., Barone, V., Mennucci, B., Petersson, G. A., Nakatsuji, H., Caricato, M., 421 Li, X., Hratchian, H. P., Izmaylov, A. F., Bloino, J., Zheng, G., Sonnenberg, J. L., Hada, 422 M., Ehara, M., Toyota, K., Fukuda, R., Hasegawa, J., Ishida, M., Nakajima, T., Honda, Y., 423 Kitao, O., Nakai, H., Vreven, T., Montgomery, J. A., Peralta, J. E., Ogliaro, F., Bearpark, 424 M., Heyd, J. J., Brothers, E., Kudin, K. N., Staroverov, V. N., Kobayashi, R., Normand, J., 425 Raghavachari, K., Rendell, A., Burant, J. C., Iyengar, S. S., Tomasi, J., Cossi, M., Rega, 426 N., Millam, J. M., Klene, M., Knox, J. E., Cross, J. B., Bakken, V., Adamo, C., Jaramillo, 427 J., Gomperts, R., Stratmann, R. E., Yazyev, O., Austin, A. J., Cammi, R., Pomelli, C., 428 Ochterski, J. W., Martin, R. L., Morokuma, K., Zakrzewski, V. G., Voth, G. A., Salvador, 429 P., Dannenberg, J. J., Dapprich, S., Daniels, A. D., Farkas, Foresman, J. B., Ortiz, J. V., 430 Cioslowski, J., \& Fox, D. J. (2009). Gaussian 09, Revision A.02. In, citeulike-article431 id:9096580). Wallingford CT.

432 García-Puente Rivas, E., Alcalde-Eon, C., Santos-Buelga, C., Rivas-Gonzalo, J. C., \& 433 Escribano-Bailón, M. T. (2006). Behaviour and characterisation of the colour during red 434 wine making and maturation. Analytica Chimica Acta, 563, 215-222.

435 Grimme, S. (2006). Semiempirical GGA-type density functional constructed with a long436 range dispersion correction. Journal of Computational Chemistry, 27, 1787-1799. 
437 Kammerer, D., Claus, A., Carle, R., \& Schieber, A. (2004). Polyphenol Screening of 438 Pomace from Red and White Grape Varieties (Vitis vinifera L.) by HPLC-DAD-MS/MS. 439 Journal of Agricultural and Food Chemistry, 52, 4360-4367.

440 Kennedy, J. A., Saucier, C., \& Glories, Y. (2006). Grape and Wine Phenolics: History and 441 Perspective. American Journal of Enology and Viticulture, 57, 239-248.

442 Mattivi, F., Guzzon, R., Vrhovsek, U., Stefanini, M., \& Velasco, R. (2006). Metabolite 443 Profiling of Grape: Flavonols and Anthocyanins. Journal of Agricultural and Food $444 \quad$ Chemistry, 54, 7692-7702.

445 Millot, M., Di Meo, F., Tomasi, S., Boustie, J., \& Trouillas, P. (2012). Photoprotective 446 capacities of lichen metabolites: A joint theoretical and experimental study. Journal of 447 Photochemistry and Photobiology B: Biology, 111, 17-26.

448 Nave, F., Bràs, N. F., Cruz, L., Teixeira, N., Mateus, N., Galembeck, S. E., Di Meo, F., 449 Trouillas, P., Dangles, O., \& De Freitas, V. (2012). The influence of a flavan-3-olic 450 substituent in the copigmentation ability of anthocyanins towards vinylcatechin dimers and 451 procyanidins. Journal of Physical Chemistry B, 116, 14089-14099.

452 Neese, F. (2012). The ORCA program system. Wiley Interdisciplinary Reviews: 453 Computational Molecular Science, 2, 73-78.

454 Neese, F., Wennmohs, F., Hansen, A., \& Becker, U. (2009). Efficient, approximate and 455 parallel Hartree-Fock and hybrid DFT calculations. A 'chain-of-spheres' algorithm for the 456 Hartree-Fock exchange. Chemical Physics, 356, 98-109.

457 Roggero, J. P., Coen, S., \& Ragonnet, B. (1986). High Performance Liquid 458 Chromatography Survey on Changes in Pigment Content in Ripening Grapes of Syrah. An 459 Approach to Anthocyanin Metabolism. American Journal of Enology and Viticulture, 37, $460 \quad 77-83$. 
461 Rustioni, L., Basilico, R., Fiori, S., Leoni, A., Maghradze, D., \& Failla, O. (2013). Grape

462 Colour Phenotyping: Develpment of a Method Based on the Reflectance Spectrum.

$463 \quad$ Phytochemical Analysis, 10.1002/pca.2434.

464 Rustioni, L., Bedgood Jr, D. R., Failla, O., Prenzler, P. D., \& Robards, K. (2012).

465 Copigmentation and anti-copigmentation in grape extracts studied by spectrophotometry 466 and post-column-reaction HPLC. Food Chemistry, 132, 2194-2201.

467 Rustioni, L., Rossoni, M., Calatroni, M., \& Failla, O. (2011). Influence of bunch exposure 468 on anthocyanins extractability from grapes skins (Vitis vinifera L.). Vitis, 50, 137-143.

469 Rustioni, L., Rossoni, M., Cola, G., Mariani, L., \& Failla, O. (2011). Bunch exposure to 470 direct solar radiation increases ortho-diphenol anthocyanins in Northern Italy climatic 471 condition. Journal Internation des Sciences de la Vigne et du Vin, 45, 85-99.

472 Rustioni, L., Rossoni, M., Failla, O., \& Scienza, A. (2013). Anthocyanin esterification in 473 Sangiovese grapes. Italian Journal of Food Science, 25, 133-141.

474 Sinnecker, S., Rajendran, A., Klamt, A., Diedenhofen, M., \& Neese, F. (2006). Calculation 475 of Solvent Shifts on Electronic g-Tensors with the Conductor-Like Screening Model 476 (COSMO) and Its Self-Consistent Generalization to Real Solvents (Direct COSMO-RS). 477 Journal of Physical Chemistry A, 110, 2235-2245.

478 Trouillas, P., Marsal, P., Siri, D., Lazzaroni, R., \& Duroux, J. L. (2006). A DFT study of 479 the reactivity of $\mathrm{OH}$ groups in quercetin and taxifolin antioxydants : The specificity of the $480 \quad 3-\mathrm{OH}$ site. Food Chemistry, 97, 10. 
483

484

485 Figure 1. Chemical structures of the five glucosylated (a) and three acylated (b) studied anthocyanins.

487

488

489

490

491

492

493

494

495

496

497

498

499

500

501

502 Figure 4. Optimized geometries of the acetyl ester (6), caffeic ester (7A; 7B) and p-coumaric

503 ester $(\mathbf{8 A}$; 8B) of malvidin 3-O-glucoside; the anthocyanidin, sugar and the acyl moieties are

504 in red, blue and green, respectively. The most relevant non-covalent intra-molecular

505 interactions between the acyl and anthocyanidin moieties are underlined by broken lines. The

506 calculations were performed with IEFPCM-B3P86/6-311+G(d,p)//COSMO-B3P86(D2)/cc-

507 pVDZ. 


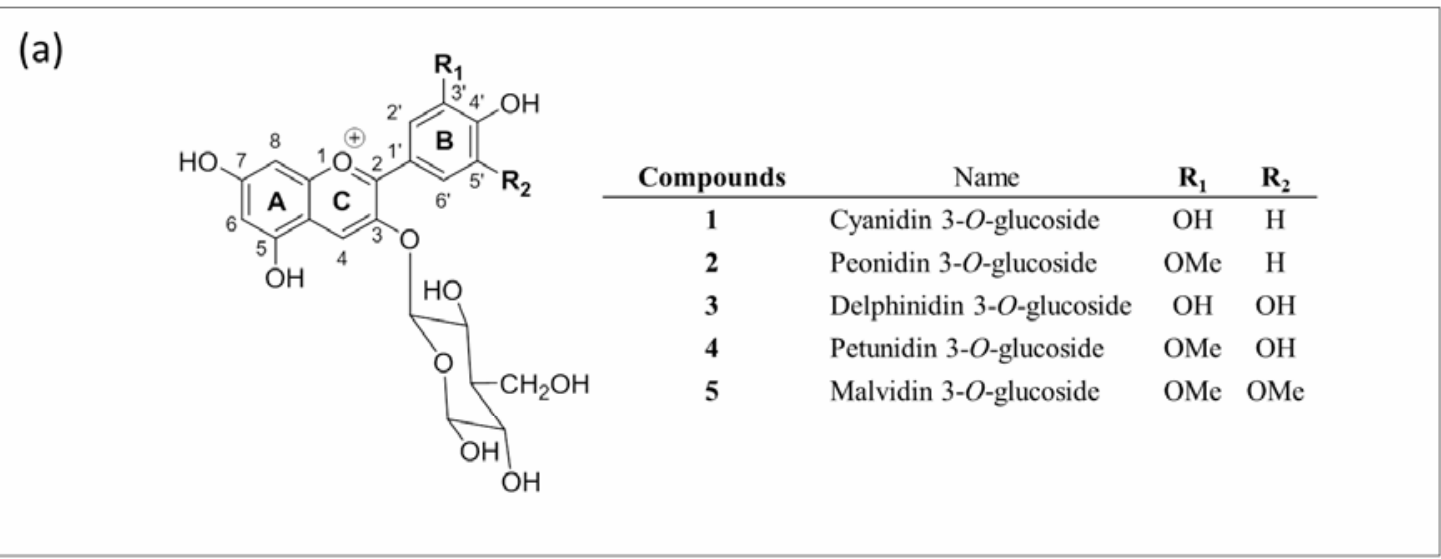

508

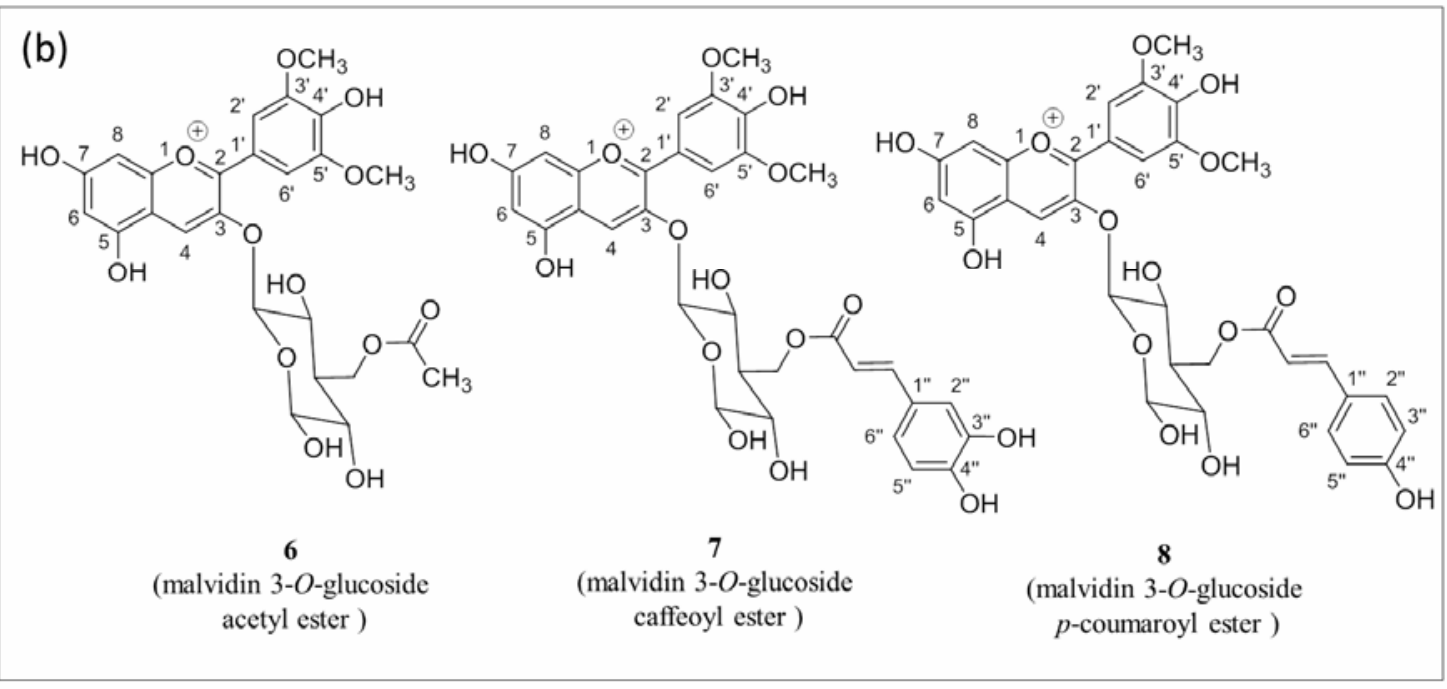



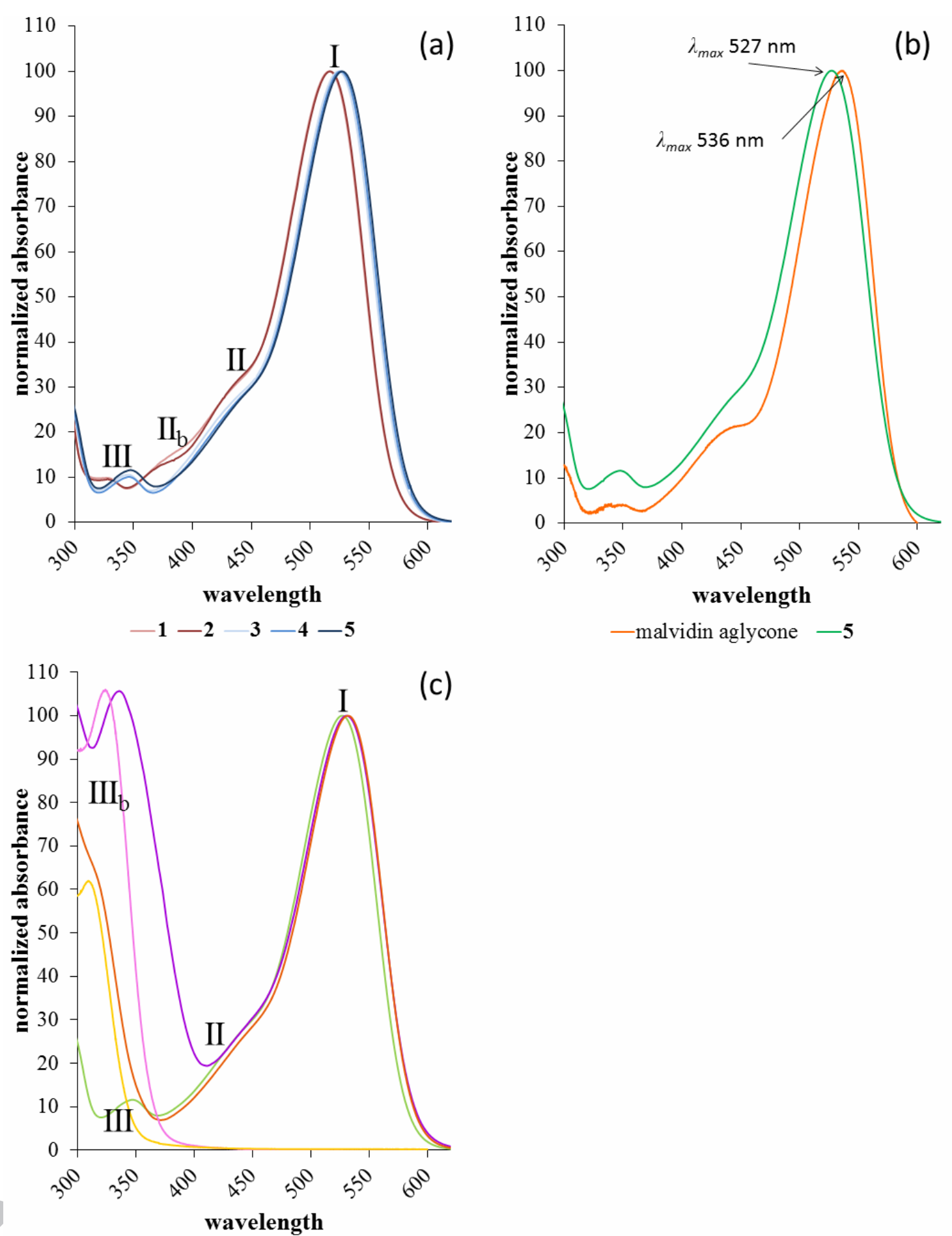

$-5-7-8-$ caffeic acid - p-coumaric acid 

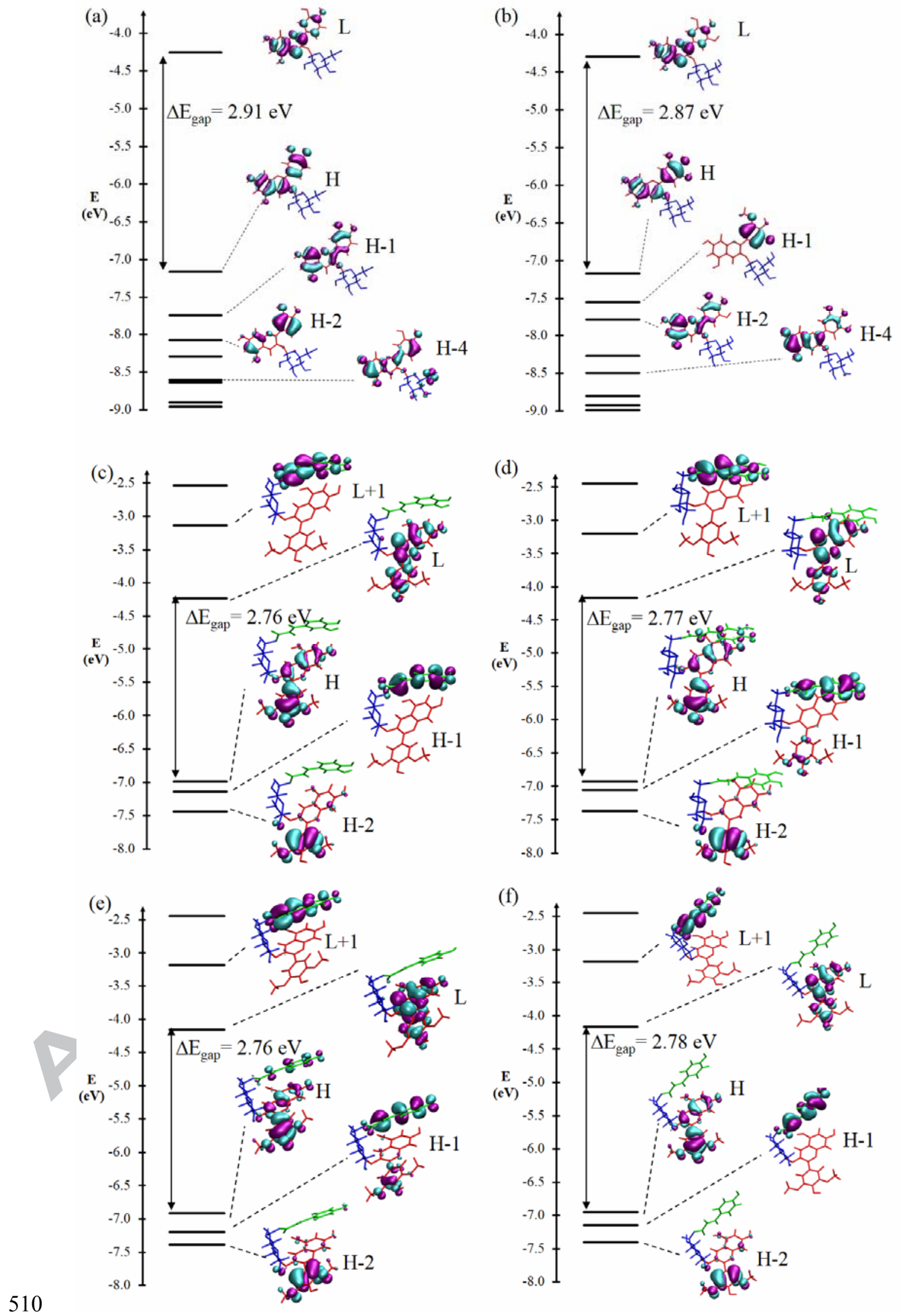


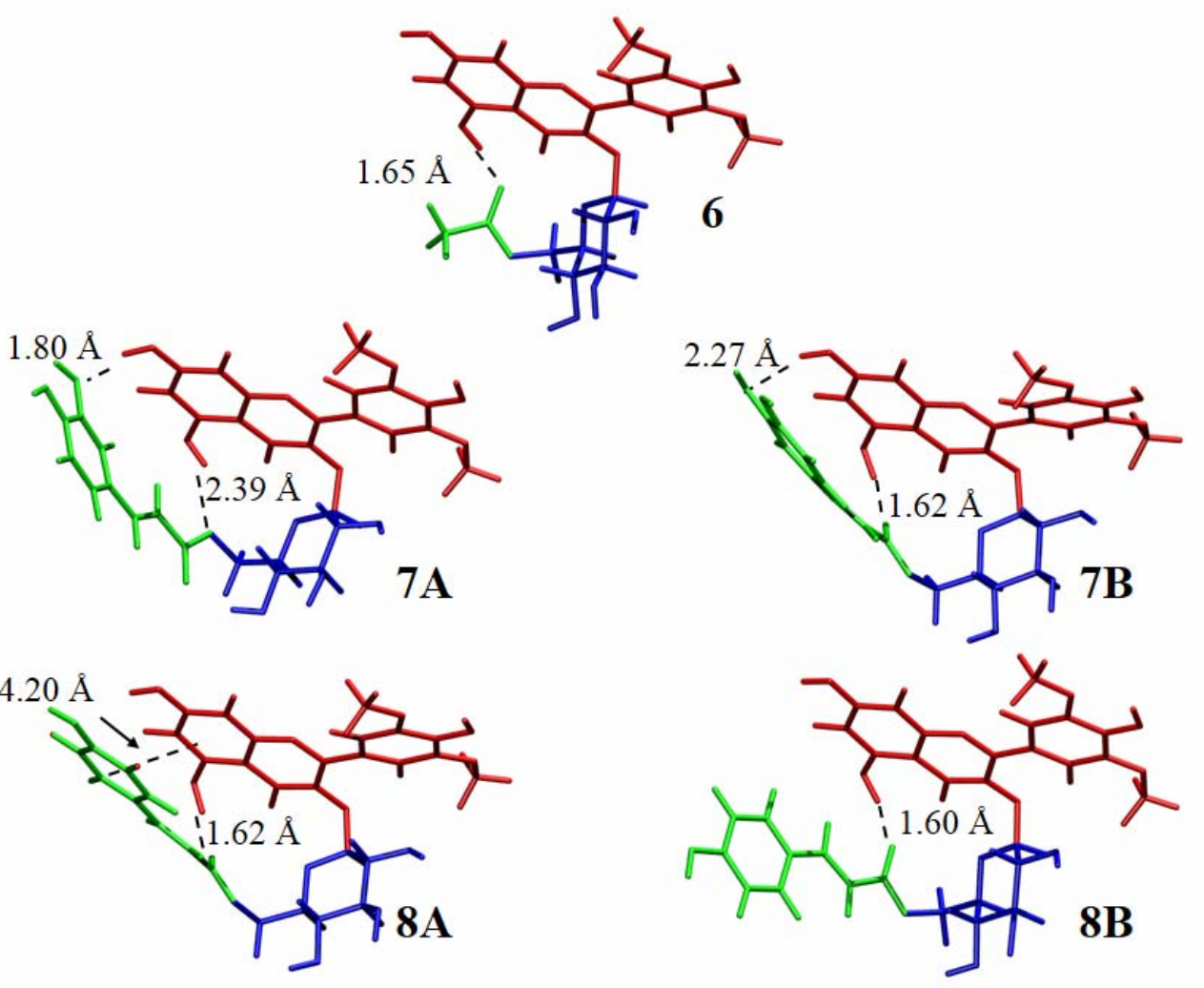

511 


\section{HIGHLIGHTS:}

513 Grape anthocyanins colors were rationalized using quantum chemistry calculations.

514 Absorption differences related to pigment substitutions were explained.

515 Intramolecular copigmentation was rationalized for acylated pigments. 
517

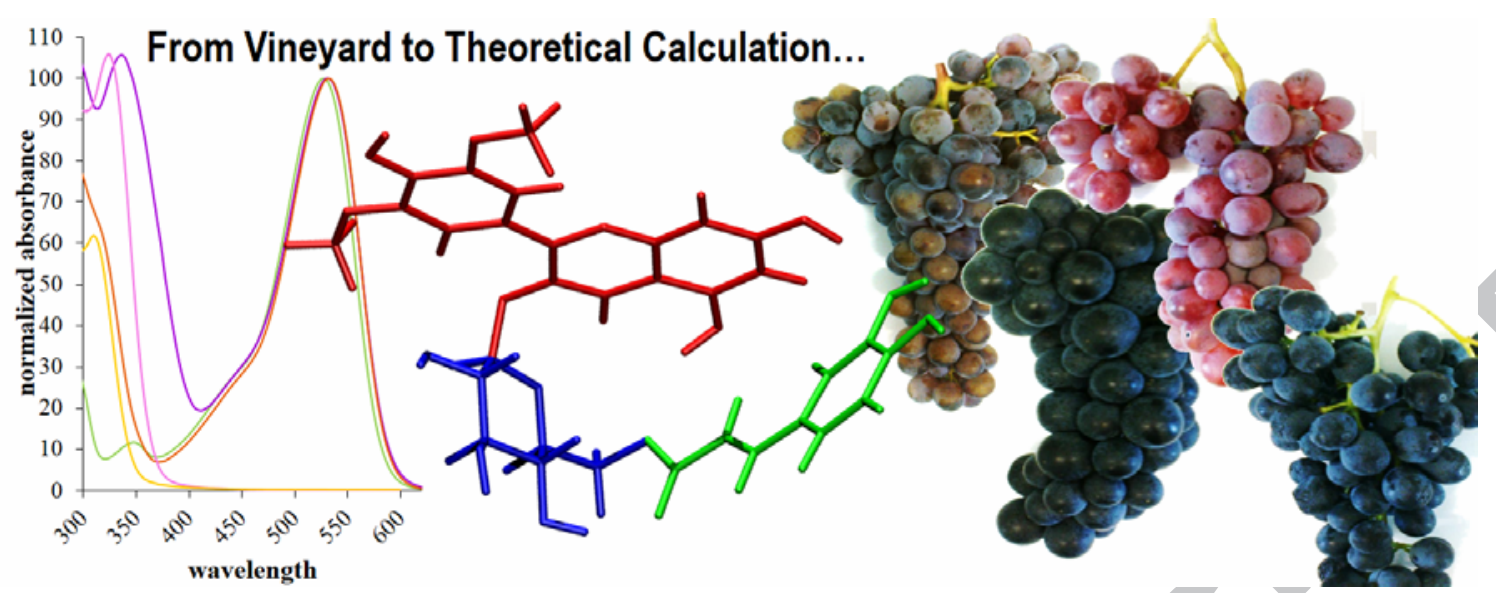

